\title{
Bioassay-guided Isolation of the Antidiabetic Active Principle from Salvia miltiorrhiza and its Stimulatory Effects on Glucose Uptake Using 3T3-L1 Adipocytes
}

\author{
Bo Hu', Ripal Amin'1, Sunil Kumar', Naveen Kunaparaju', Steven M. Graham², Michael A Barletta ${ }^{2}$ and William Zito $\mathbf{S}^{2, *}$ \\ ${ }^{1}$ Department of Pharmaceutical Sciences, College of Pharmacy and Health Professions, St. John's University, Jamaica, NY 11439, USA \\ ${ }^{2}$ Department of Chemistry, College of Liberal Arts and Sciences, St. John's University, 8000 Utopia Parkway, Jamaica, NY 11439, USA
}

\begin{abstract}
Natural products, which reduce hyperglycemia by enhancing the glucose uptake in peripheral tissues, have been considered to be effective for treatment of Type-2 Diabetes Mellitus. Salvia miltiorrhiza (Labiatae), danshen, has been widely used traditional Chinese medicine for the treatment of various cardiovascular and cerebrovascular diseases. In the present study, different extracts of Salvia miltiorrhiza root were investigated for their ability to enhance glucose uptake in differentiated 3T3-L1 adipocytes. An in vitro bioassay guided fractionation approach was adapted to isolate the active principle of Salvia miltiorrhiza using extensive column chromatographic techniques. The structure of active compound was elucidated using various spectroscopic methods (ESI-MS, MALDI-ToF, ${ }^{1} \mathrm{H}-\mathrm{NMR},{ }^{13} \mathrm{C}-\mathrm{NMR}, \mathrm{COSY}$, TOCSY, HETCOR) and determined to be magnesium salt of salvianolic acid B (SAB). SAB showed concentration dependent increase in glucose uptake in 3T3-L1 adipocytes. The efficacy of the active principle was also evaluated for its antidiabetic activity in streptozotocin-induced diabetic rats. SAB $(25 \mathrm{mg} / \mathrm{kg})$ significantly improved the glucose tolerance in diabetic rats $\left({ }^{*} p<0.05,{ }^{* *} p<0.01\right)$. The SAB treatment group showed significantly lower $\left({ }^{*} p<0.05\right)$ blood glucose levels over $120 \mathrm{~min}$ as compared to diabetic control group. Thus, these results suggested that $S A B$ has the potential to be developed as a potential glucose-lowering agent by increasing glucose uptake in peripheral tissues in the treatment of diabetes mellitus.
\end{abstract}

Keywords: Salvia miltiorrhiza; Glucose uptake; 3T3-L1 adipocytes; ESI-MS; NMR; Diabetes mellitus; OGTT

List of Abbreviations: ODS: Octadodecylsilyl; LC-MS/MS: Liquid Chromatography Coupled to Tandem Mass Spectrometry; MALDIToF: Matrix-Assisted Laser Desorption/Ionization Time of Flight; ESI: Electrospray Ionization; NMR: Nuclear Magnetic Resonance; COSY: Correlated Spectroscopy; TOCSY: Total Correlated Spectroscopy; HETCTOR: Heteronuclear Correlation Spectroscopy; IR: Infrared; SAB: Salvianolic acid B

\section{Introduction}

Type 2 diabetes mellitus is a chronic metabolic disorder characterized by impaired insulin secretion and insulin sensitivity, which poses an imminent threat to become a worldwide epidemic according to world health organization [1-3]. Type 2 diabetes mellitus is associated with severe complications such as hypertension, dyslipidemia, microvascular and macrovascular cardiovascular diseases [4-6]. Insulin plays a regulatory role in this disease by stimulating the uptake of blood glucose into peripheral tissues through glucose transporters and the promotion of lipid biosynthesis in adipocytes [7]. Insulin resistance causes decrease in peripheral glucose disposal resulting in increased levels of blood glucose [7]. Some of the currently available antidiabetic drugs improve blood glucose levels by increasing the glucose uptake in peripheral tissues. However such drugs are associated with adverse side effects, which limit their use in diabetic patients. Therefore it is highly desirable to discover antidiabetic agents that improve blood glucose levels with minimal side effects.

Salvia miltiorrhiza (Labiatae), danshen, is an annual sage mainly found in china and neighboring countries. The dried root and its preparations are currently being used in china to treat patients with cardiovascular and cerebrovascular complications [8]. Many compounds have been isolated from Salvia miltiorrhiza roots, which could be classified as lipid soluble tanshinones and water-soluble phenolic acid compounds [9]. Among phenolic acids, salvianolic acid B is a major component of $S$. miltiorrhiza and extensive pharmacological studies have been reported for this compound. Salvianolic acid B inhibited the amyloid formation of human islet amyloid polypeptide and protects pancreatic beta cells against cytotoxicity [10]. Many authors have studied the effect of salvianolic acid B on different organ systems in animals as well as in humans. Salvianolic acid B showed beneficial and protective effect to brain from ischemia-reperfusion injury in animal studies [11]. In addition, salvianolic acid B has been shown to inhibit platelet aggregation [12] as well as cause oxidative modification of low-density lipoprotein (LDL) thereby, resulting into decreased uptake of LDL by cultured macrophages [13]. Furthermore, salvianolic acid B has been shown to stimulate the nitric oxide production of the endothelial cell [14] and inhibition of angiotensin IIinduced hyperplasia [15]. It significantly inhibited the activity of stressactivated protein (SAP) kinase [16]. Magnesium salt of salvianolic acid $\mathrm{B}$ has been shown to possess potent hepatoprotective activity and shows an improved effect on uremic symptoms [17,18]. An in vitro study also revealed that salvianolic acid B is an excellent scavenger for free radicals, both cation radicals and anion radicals [19]. It has been reported that salvianolic acid B has potent inhibitory effects on lipid or biomembrane peroxidation in a superoxide anion generating system $[20,21]$.

Recent studies focused on S. miltiorrhiza and/or salvianolic acid $B$ linked their beneficial effects in treatment of diabetes mellitus and

*Corresponding author: William Zito S, Department of Chemistry, College of Liberal Arts and Sciences, St. John's University, Jamaica, NY 11439, USA, Tel: 1-718-990-1632; 718-990-5046; Fax: 1-718-990-1877; E-mail: zitos@stjohns.edu

Received June 27, 2014; Accepted August 11, 2014; Published August 13, 2014

Citation: Hu B, Amin R, Kumar S, Kunaparaju N, Graham SM, et al. (2014) Bioassay-guided Isolation of the Antidiabetic Active Principle from Salvia miltiorrhiza and its Stimulatory Effects on Glucose Uptake Using 3T3-L1 Adipocytes. Med chem 4: 592-597. doi:10.4172/2161-0444.1000199

Copyright: (c $2014 \mathrm{Hu} \mathrm{B}$, et al. This is an open-access article distributed under the terms of the Creative Commons Attribution License, which permits unrestricted use, distribution, and reproduction in any medium, provided the original author and source are credited. 
its associated manifestations. Chronic treatment with S. miltiorrhiza has been shown to inhibit the progression of diabetic nephropathy in streptozotocin induced diabetic animals along with down regulation of TSP- 1 and TGF- $\beta 1$ in myocardial tissue, thereby improving the heart function of diabetic rats and protecting against cardiomyopathy [22]. Previous studies on natural plant extracts such as M. charantia, L. speciosa, S. aqueum, showed their ability to induce glucose uptake in 3T3-L1 adipocytes in vitro [6,23,24]. To date, there is no literature showing the direct effects of different extracts or isolated compounds of S. miltiorrhiza on glucose uptake in 3T3-L1 adipocytes. Henceforth the objective of present study was to elucidate the active principle of $S$. miltiorrhiza responsible for stimulating glucose uptake using bioassayguided fractionation approach and access its emphasis in vivo.

\section{Material and Methods}

\section{Materials}

The dry decoction of salvia root was obtained and certified by Tong Ren Tang (Beijing, P.R. China) and New York Tong Ren Tang (Flushing, NY). The voucher specimen has been retained at the department of Pharmaceutical sciences at St. John's University, New York. Glucose, streptozotocin (STZ), insulin (IS), dexamethasone (DEX) and 3-Isobutyl-1-methylxanthine (IBMX) were purchased from Sigma-Aldrich (St. Louis, MO). 2-[1, 2- ${ }^{3} \mathrm{H}(\mathrm{N})$-Deoxy-D-glucose (2DG) was purchased from PerkinElmer (Waltham, MA). Male SpragueDawley rats were purchased from Taconic Farms (Germantown, NY). Salvianolic acid B standard was purchased from Ivy Fine Chemicals (Cherry Hill, NJ). 'Bakers' Silica gel (40 $\mu \mathrm{m}$ flash chromatography packing) was purchased from VWR International (San Dimas, CA). White quartz sand, Davisil' silica gel (grade 62, pore size $150 \AA$, 60 200 mesh) and Sephadex (LH-20) were purchased from Sigma-Aldrich (St. Louis, MO). Uniplate ${ }^{\varpi}$ silica gel GF plate and preparative silica gel GF plate were purchased from Analtech, Inc (Newark, DE). All other reagents were of analytical grade and used without further purification.

\section{Other instruments}

HPLC system (Shimadzu), equipped with Waters ${ }^{\mathrm{TM}} 717$ plus autosampler, Perkin-Elmer Spectrum One FT-IR Spectrometer, Shimadzu GCMS-QP5050A Gas Chromatography Mass Spectrometer, Bruker Daltonics ${ }^{\circledR}$ Matrix-Assisted Laser Desorption/Ionization Time of Flight (MALDI-ToF) Mass Spectrometer were used. ${ }^{1} \mathrm{H}$ NMR, ${ }^{13} \mathrm{C}$ NMR and APT (attached proton test) spectra were recorded on a $400 \mathrm{MHz}$ Brucker instrument with trimethylsilane as an internal standard. Chemical shifts were recorded as ppm $(\delta)$. LC-MS/MS data was obtained from API 3000 LC-MS/MS system. Melting points were determined using a MEL-TEMP II melting point apparatus. Elemental analysis was performed by Atlantic Microlab Inc (Norcross, GA).

\section{Isolation of S4LH06 from salvia root}

The dry decoction of crushed salvia root were powdered and passed through a 40 -mesh sieve. The powder ( 40 g) was sonicated with $70 \%$ ethanol $(\mathrm{EtOH})$ for $6 \mathrm{hrs}$ at room temperature. The ethanolic extract was filtered and concentrated under reduced pressure below $40^{\circ} \mathrm{C}$ and lyophilized to yield dry residue [4,25]. The crude EtOH extract was suspended in distilled water and extracted with chloroform in a separatory funnel. The chloroform fraction then concentrated under reduced pressure below $30^{\circ} \mathrm{C}$, and designated as the chloroform fraction. The remaining aqueous layer was subjected to extraction with ethyl acetate (EtOAc) in similar manner as chloroform. The EtOAc layer then concentrated under reduced pressure below $30^{\circ} \mathrm{C}$ and designated as the ethyl acetate fraction. The remaining aqueous layer was extracted with n-butanol in similar manner discussed above and collected as n-butanol fraction and aqueous fraction. The aqueous fraction from n-butanol extraction was precipitated by $100 \%$ ethanol, yielding water precipitate (WP) and water supernatant (WS). The n-butanol fraction was subjected to a silica gel $(40 \mu \mathrm{m})$ column and eluted with a $20 \%$ stepwise gradient with $\mathrm{EtOH}$ in chloroform. The fraction eluted with $100 \% \mathrm{EtOH}$ was then separated by using silica gel (grade 62, pore size $150 \AA$, 60-200 mesh) flash chromatography and eluted with a stepwise gradient of ethanol in chloroform. Seven fractions (S0-S6) were collected and concentrated under reduced pressure below $30^{\circ} \mathrm{C}$. The fraction eluted with $100 \%$ ethanol (S4 fraction) was further passed through a sephadex LH-20 column and eluted with $\mathrm{MeOH}-\mathrm{H}_{2} \mathrm{O}$ (40:60/v:v). Six different fractions (S4LH01S4LH06) were collected and lyophilized to dry residues. S4LH06 was further purified using preparative thin layer chromatography (TLC) plate (mobile phase; chloroform: ethyl acetate: formic acid; 1:1:0.1/v:v) and sephadex LH-20 column to yield purified light yellow amorphous powder of S4LH06. The final yield of S4LH06 was 0.03 to $0.06 \%$ with a purity $>98 \%$ based on TLC, HPLC, elemental analysis and ESI-MS.

\section{Structure elucidation and characterization of purified S4LH06}

The structure of purified S4LH06 was determined to be magnesium salt of salvianolic acid $\mathrm{B}[9,26,27]: \mathrm{C}_{36} \mathrm{H}_{28} \mathrm{O}_{16} \mathrm{Mg}$. It was identified and confirmed by comparative analysis of its ESI-MS, ${ }^{1} \mathrm{H}-\mathrm{NMR},{ }^{13} \mathrm{C}-\mathrm{NMR}$, Correlated spectroscopy (COSY), total correlated spectroscopy (TOCSY), heteronuclear correlation spectroscopy (HETCOR), IR spectrum, HPLC chromatogram and mass spectral data with authentic sample data and/or with literature data.

\section{Cell culture}

3T3-L1 fibroblasts were obtained from American Type Culture Collection (ATCC, Manassas, VA) and cultured in DMEM supplemented with $10 \%$ bovine serum (Invitrogen Corp, Carlsbad, $\mathrm{CA}$ ) in $5 \% \mathrm{CO}_{2}$ at $37^{\circ} \mathrm{C}$. Differentiation was induced by treating the cells with DMEM containing 3-Isobutyl-1-methylxanthine (IBMX, 0.5 $\mathrm{mM}$ ), dexamethasone (DEX, $0.25 \mu \mathrm{M}$ ), insulin (IS, $1 \mathrm{mg} / \mathrm{l}$ ), and $10 \%$ BS for 72 hours. The cells were refed with DMEM containing 10\% BS and $1 \mathrm{mg} / \mathrm{L}$ IS for the following 48 hours after which cells were kept in the maintenance media (DMEM $+10 \%$ BS). More than $90 \%$ of the cells expressed adipocyte phenotype between 11 and 14 days after the initiation of differentiation and were used for the glucose uptake experiments.

\section{2-Deoxyglucose uptake assay}

Glucose uptake was determined as the rate of $2-\left[1,2-{ }^{3} \mathrm{H}(\mathrm{N})\right]$ Deoxy-D- glucose uptake, using a modification of a previous method with a few modifications $[28,29]$. Confluent and differentiated 3T3L1 adipocytes were washed (thrice) and incubated with serum free DMEM for 2 hours. After 2 hrs, cells were washed thrice with DPBS and incubated with DPBS (glucose free incubation) for 30 minutes at $37^{\circ} \mathrm{C}$. After glucose free incubation, the cells were incubated with DPBS containing different fractions of salvia root, purified compounds or control for 10 minutes at $37^{\circ} \mathrm{C}$. Glucose uptake was initiated by addition of $2-\left[1,2-{ }^{3} \mathrm{H}(\mathrm{N})\right]-$ Deoxy-D- glucose $(1 \mu \mathrm{Ci} / \mathrm{ml})$ in each well. After $10 \mathrm{~min}$, cells were rinsed three times with cold PBS to stop the transport then lysed by incubating the samples with $1 \%$ Triton X100 for $30 \mathrm{~min}$ at room temperature. Cell lysates of each well were mixed with aqueous scintillation fluid and the amount of radioactivity incorporated into cells were measured in a liquid scintillation counter and normalized with its protein content. Protein concentration of each sample was quantified using a BCA protein assay kit. Final data were expressed as the percentage of control. Insulin concentration response 
curve was performed (data not shown) and insulin $(1 \mu \mathrm{M})$ was used as a positive control in each glucose uptake experiment.

\section{Glucose tolerance test}

The Animal Care Committee of St. John's University, NY approved all animal protocols. Male Sprague-dawley (SD) rats (body weight $175 \sim 200 \mathrm{~g})$ were fasted overnight and injected with streptozotocin (STZ, i.p.) dissolved in citrate buffer ( $\mathrm{pH} \mathrm{4.5)} \mathrm{at} \mathrm{a} \mathrm{dose} \mathrm{of} 45 \mathrm{mg} / \mathrm{kg}$. Two days after STZ injection, rats with blood glucose concentration higher than $300 \mathrm{mg} / \mathrm{dl}$ (at fasting state) were considered as diabetic and included in the present study. They were randomized in control (diabetic control) and test groups. In an oral glucose tolerance test, 16 hours fasted animals were intraperitoneally dosed with test compound (S4LH06, $25 \mathrm{mg} / \mathrm{kg}$ ) or saline control at $-15 \mathrm{~min}$ followed by oral gavage of glucose $(2.0 \mathrm{~g} / \mathrm{kg})$. Blood glucose levels were measured at $0,15,30,45,60,90$, and 120 min using glucose meter $[25,30]$. The relative glucose percentage change was determined using the following equation: glucose level at particular time point $(\mathrm{mg} / \mathrm{dl}) / \mathrm{glucose}$ level at zero time point $(\mathrm{mg} / \mathrm{dl}) * 100$.

\section{Statistical analysis}

Data are expressed as mean \pm standard error of the mean (SEM), and $p$-values less than 0.05 were considered significant. One-way analysis of variance (ANOVA) was performed in compound treatment. Prism Graph-Pad (Version 5.0) software was used for statistics and plotting.

\section{Results}

\section{Glucose uptake activity of salvia miltiorrhiza fractions}

The decoction pieces of salvia root were extracted with $70 \%$ aqueous EtOH. The crude extract was then extracted with chloroform, ethyl acetate and n-butanol using a separatory funnel. We initially tested all the fractions of salvia root $(70 \% \mathrm{EtOH}$, chloroform, ethyl acetate, n-butanol, water supernatant and water precipitate) at $0.2 \mathrm{mg} /$ $\mathrm{ml}$ to determine their effect on glucose uptake in differentiated 3T3L1 adipocytes. All fractions (except WS, and WP) showed significant potentiation of glucose uptake (ranging between $120 \%$ and $187 \%$ ) as compared to DPBS control $(100 \%, \mathrm{p}<0.05$, Figure 1$)$. The n-butanol $(\mathrm{nBu})$ fraction was the most active with respect to glucose uptake (Figure 1). This fraction was chromatographed over a silica gel column $(40 \mu \mathrm{m})$ and separated into ten fractions. All ten fractions (Tested concentration: $0.2 \mathrm{mg} / \mathrm{ml}$ ) were examined for their effect on glucose uptake. The most active subfraction, 100\% EtOH (Figure 2, $\mathrm{p}<0.001$ ), showed significant increase in glucose uptake, which then rechromatographed on a second silica gel column (Grade 62, pore size $150 \AA$, 60-200 mesh) and separated into seven fractions (S0-S6). Fractions S3, S4 and S5 (Tested concentration: $0.1 \mathrm{mg} / \mathrm{ml}$ ) showed significant increase in glucose uptake (data not shown).

The most active subfraction, S4, was subjected to sephadex LH-20 column and separated into six fractions (S4LH01-S4LH06). Further purification of the most active fraction, S4LH06 (Figure 3), by preparative thin layer chromatography and sephadex LH-20 column resulted in the identification of the magnesium salt of salvianolic acid B.

\section{Effect of purified S4LH06 on glucose uptake in 3T3-L1} adipocytes

Treatment of fully differentiated 3T3-L1 adipocytes with increasing doses of purified compound S4LH06 resulted in significant enhancement in glucose uptake (Figure 4). S4LH06 increased glucose

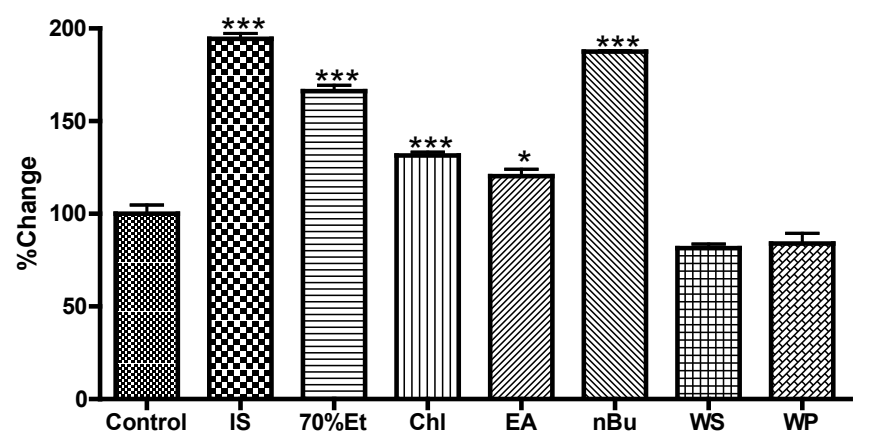

Figure 1: Glucose Uptake Activity of Salvia Root Fractions resulted from Liquid-Liquid Extraction, Test concentration $0.2 \mathrm{mg} / \mathrm{ml}$. *v. control $p<0.05$, *** vs. control p<0.001. (IS:Insulin; ET:Ethanol; Chl:Chloroform; EA:Ethylacetate; nBu: Normal Butanol; WS: Water Supernatant; WP: Water Precipitate).

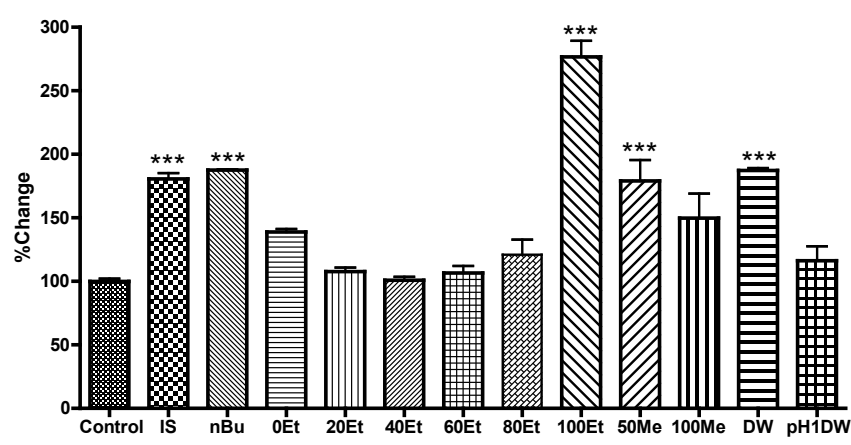

Figure 2: Glucose Uptake Activity of Fractions derived from $\mathrm{nBu}$ fraction by Silica gel $(40 \mu \mathrm{m})$ Flash Chromatography, Test concentration: $0.2 \mathrm{mg} / \mathrm{ml}$, *** vs. control p<0.001 (IS:Insulin; nBu:Butanol; Et: Ethanol; Me:Methanol; DW:Distilled Water)

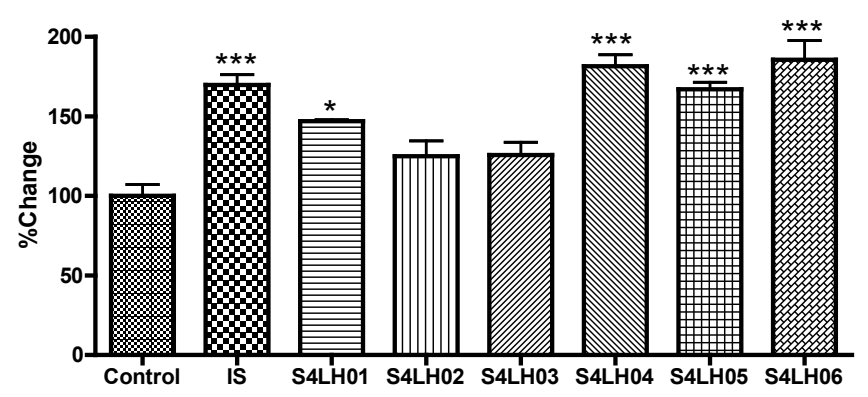

Figure 3: Glucose Uptake Activity of Fractions derived from S4 fraction by Sephadex LH-20 Liquid Chromatography, Test concentration: $0.1 \mathrm{mg} / \mathrm{ml}$, *vs. control $p<0.05,{ }^{* * *}$ vs. control $p<0.001$ (IS: Insulin).

uptake in a concentration dependent manner from ranging from $102 \%$ to $196 \%$ as compared control (100\%) over the concentration range of $0.01 \mathrm{mg} / \mathrm{ml}-2 \mathrm{mg} / \mathrm{ml}$. S4LH06 $(1 \mathrm{mg} / \mathrm{ml})$ showed highest enhancement of glucose uptake activity of $196 \%$ as compared to control. Higher concentration of S4LH06 $(2 \mathrm{mg} / \mathrm{ml})$ did not further increase glucose uptake activity in 3T3-L1 adipocytes.

\section{Identification of active compound S4LH06}

Based on the spectroscopic analysis of the purified active compound (S4LH06), obtained from the n-butanol fraction of the ethanolic extract of Salvia Miltiorrhiza, was identified as magnesium salt of Salvianolic acid B. The purity of S4LH06 determined by TLC and 


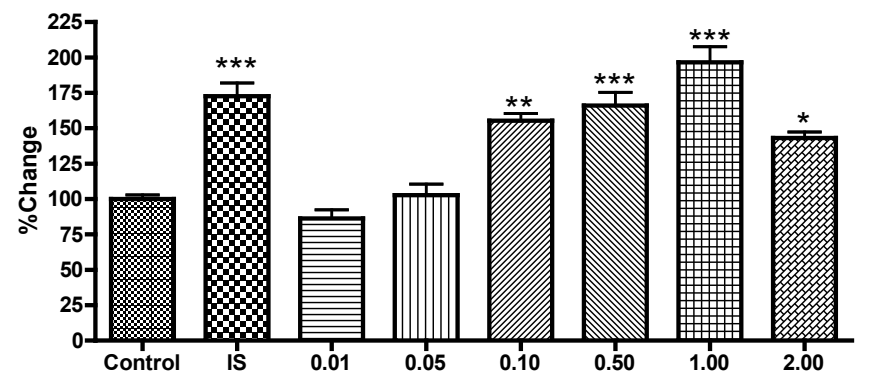

Figure 4: Glucose Uptake Activity of S4LH06 (mg/ml), *vs. control $p<0.05,{ }^{* *}$ vs. control $p<0.01,{ }^{* * *}$ vs. control $p<0.001$. (IS:Insulin).

HPLC analysis. The HPLC chromatogram of S4LH06 showed a single peak at $1.6 \mathrm{~min}$ (Column, HILIC; Mobile phase, acetonitrile: water, 9:1/v:v ) and at 6 min (Column, HILIC; Mobile phase, chloroform: ethyl acetate, 1:1/v:v). TLC of S4LH06 showed a single blue spot under UV light after being sprayed with $5 \% \mathrm{FeCl}_{3}-\mathrm{MeOH}$. The matrixassisted laser desorption/ionization-time of fly (MALDI-ToF) and Liquid chromatography coupled to negative electrospray ionization (ESI) tandem mass spectrometry (LC-MS/MS) were used to determine the molecular weight of S4LH06. MALDI-MS analysis of S4LH06 in positive mode showed 3 mass peaks $[\mathrm{M}+1]^{+}$, which correspond to $\mathrm{m} / \mathrm{z}$ 521, 741, and 908. ESI-MS data of S4LH06 in negative mode showed molecular ion peaks [M-1] of $m / z 519$ and 739 along with highest intense peak $\mathrm{m} / z$ 717. The elemental analysis of S4LH06 showed only $\mathrm{C}, 56.28 ; \mathrm{H}, 4.44 ; \mathrm{O}, 36.31$. Based on the mass spectrum analysis and elemental analysis of S4LH06, the molecular weight of S4LH06 was determined to be $740[9,26,27]$. The molecular formula of S4LH06 was assigned as $\mathrm{C}_{36} \mathrm{H}_{28} \mathrm{O}_{16} \mathrm{Mg}$. The presence of magnesium was determined by flame atomic absorption analysis.

Magnesium salt of salvianolic acid $\mathrm{B}$ : light yellow amorphous powder; 1H-NMR (DMSO-d6, $400 \mathrm{MHz}) \delta 10.2-8.5(7 \mathrm{H}, \mathrm{m}, \mathrm{Ar}-\mathrm{OH})$, $7.5(1 \mathrm{H}, \mathrm{d}, \mathrm{J}=15.9 \mathrm{~Hz}, \mathrm{CH}=\mathrm{CH}), 7.3-6.2(11 \mathrm{H}, \mathrm{m}, \operatorname{ArHx} 8), 6.3(1 \mathrm{H}, \mathrm{d}$, $\mathrm{J}=15.9 \mathrm{~Hz}, \mathrm{CH}=\mathrm{CH}), 5.3(1 \mathrm{H}, \mathrm{d}, \mathrm{J}=4.9 \mathrm{~Hz}, \operatorname{Ar}-\mathrm{CH}(\mathrm{O})-\mathrm{C}), 5.0(2 \mathrm{H}, \mathrm{m}$, $\mathrm{CH}-\mathrm{COOx} 2), 4.4(1 \mathrm{H}, \mathrm{d}, \mathrm{J}=4.9 \mathrm{~Hz}, \operatorname{Ar}-\mathrm{C}(\mathrm{O})-\mathrm{CH}-), 3.0-2.8(4 \mathrm{H}, \mathrm{m}$, $-\mathrm{CH}_{2} \mathrm{x} 2$ ); 13C-NMR (MeOH-d4, $\left.400 \mathrm{MHz}\right) \delta 176.5,175.7,171.5,167.5$, 147.7, 145.1, 145.0, 144.5, 144.3, 143.4, 143.2, 141.1, 132.7, 129.8, 129.3, $125.4,123.3,120.7,120.6,119.9,117.0,116.6,116.2,115.84,115.78$, $115.2,114.99,114.94,112.2,86.9,77.6,76.7,57.3,37.4,36.9$; ESI-MS (Q1 mass, negative mode) 827.2, 815.2, 743.9, 739.2, 717.5, 537.9, MS2 of peak ( $\mathrm{m} / \mathrm{z} 717)$ : 537.1, 518.5, 339.0, 320.5, 294.9. The two-dimension ${ }^{1} \mathrm{H} \mathrm{NMR}$ of S4LH06 in MeOH- $\mathrm{d}_{4}$, COSY, was performed to determine the connectivity of protons by their spin-spin coupling. A detailed coupling between protons was determined by performing selective 1D-TOCSY. APT was performed to determine the number of protons attached to each carbon and the carbon-proton connections were confirmed by 2-D HETCOR. S4LH06 showed IR absorption bands at $3367 \mathrm{~cm}^{-1}$ and $1719 \mathrm{~cm}^{-1}$, suggesting the presence of hydroxyl $(\mathrm{OH})$ and carbonyl $(\mathrm{C}=\mathrm{O})$ groups in the molecule.

Based on ${ }^{1} \mathrm{H}$ NMR, COSY, TOCSY, ${ }^{13} \mathrm{CNMR}$, APT, HETCOR, IR spectrum data, it was concluded that S4LH06 has four aromatic rings, three ethyl linkers, one trans-alkene, four carbonyl groups and seven-eight hydroxyl groups (thirteen aromatic protons, eight aliphatic protons, four carbonyl carbons, and twenty six aromatic carbons). Salvianolic acid B [31] contains all the proposed moieties of S4LH06. The flame atomic absorption analysis revealed that S4LH06 $\left(\mathrm{C}_{36} \mathrm{H}_{28} \mathrm{O}_{16} \mathrm{Mg}, \mathrm{MW}=740\right)$ is a magnesium salt of salvianolic acid $\mathrm{B}$. Thin layer chromatographic analysis of both S4LH06 and standard salvianolic acid B showed a single blue spot after being sprayed with
$5 \% \mathrm{FeCl}_{3}-\mathrm{MeOH}$. ESI-MS analysis of S4LH06 and standard salvianolic acid $\mathrm{B}$ showed the identical mass peaks with a molecular ion of $m / z$ [M1] at 519, 739 and 717 (highest intensity). ${ }^{1} \mathrm{H}$ and ${ }^{13} \mathrm{CNMR}$ spectrum data of S4LH06 were mostly superimposable to the standard salvianolic acid B.

\section{Oral glucose tolerance test (OGTT)}

To investigate whether S4LH06 could improve glucose tolerance in vivo upon single dose administration, we tested S4LH06 in a streptozotocin induced diabetic rat model. Based on oral glucose tolerance test analyses, S4LH06 (25 mg/kg, i.p) improved glucose tolerance as compared to vehicle control (Saline, i.p) (Figure 5). At time points of 30,45, and $60 \mathrm{~min}$ after glucose challenge, S4LH06 reduced $\%$ relative glucose compared to control from an average of $187 \%$ to an average of $106 \%$ with $\mathrm{p}<0.01$ (30-min time point), from $184 \%$ to $104 \%$ ( $p<0.01,45$ min time point) and from $176 \%$ to $110 \%$ with $p<0.05$ (60min time point), respectively. Integrated area under the glucose curve over 120 min $\left(\mathrm{AUC}_{\text {glucose }}\right)$ of S4LH06 treatment group was significantly lower $(p<0.05)$ as compared to diabetic control group (Figure 5 ). Taken together, the results from this experiment demonstrated that S4LH06 may possess a hypoglycemic activity in vivo.

\section{Discussion}

The present study is the first to report the bioassay-guided

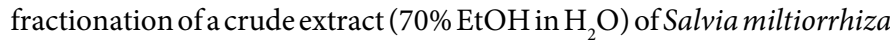
roots, which led to the isolation, characterization, and identification of phenolic acid, magnesium salt of salvianolic acid B (SAB) and its effect on glucose uptake in vitro using 3T3-L1 adipocytes. Salvianolic acid B, a tetramer of caffeic acid, is a major phenolic product found in S. miltiorrhiza [32-34]. It consists of three danshensu units and one caffeic acid unit bound by an ester linkage (Zhao et al.,). There is an increasing awareness and interest in the antioxidant properties and other positive effects of phenolic acids in prevention of various human diseases. Phenolic acids present in Salvia miltiorrhiza have been shown to possess protective properties against amyloid $\beta$-induced cytotoxicity, indicative of beneficial effects of this herb in Alzheimer's disease (AD) treatment [33]. The root of S. miltiorrhiza is widely used in Asian countries for the treatment of coronary heart disease, cerebrovascular disease, hypertension, chronic renal failure, and dysmenorrhea and as cytotoxic against human tumor cell lines [34-37].

In present study, magnesium salt of salvianolic acid B was isolated, purified and characterized from S. miltiorrhiza roots by column chromatography using silica gel, sephadex LH-20 followed by spectroscopic analysis. Several methods have been reported for
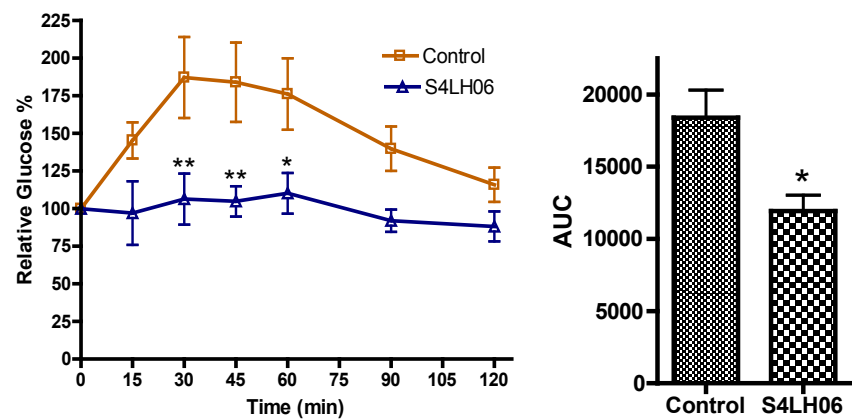

Figure 5: Glucose Tolerance Test in STZ-Rats. Control group, saline with IP; test group, S4LH06 in saline $25 \mathrm{mg} / \mathrm{kg}$ with IP. Left, relative glucose change after glucose load $(2 \mathrm{~g} / \mathrm{kg})$; right, area under the curve $\left(A \cup \mathrm{C}_{\text {glucose }}\right)$ of control and test group. ${ }^{*} v s$. control $p<0.05,{ }^{* *} v s$. control $p<0.01$. 
isolation of salvianolic acid from S. miltiorrhiza such as preparative high-speed counter-current chromatography (HSCCC) $[9,26]$ and microwave-assisted extraction method coupled reverse-phase highperformance liquid chromatographic (RP-HPLC) method with UV detection [38]. The in vitro bioassay data demonstrated that different fractions of S. miltiorrhiza such as ethyl acetate, chloroform, n-butanol, and water fractions significantly increased the glucose uptake in 3T3-L1 adipocytes. (Figures 1-3) Further purification of n-butanol fraction of S. miltiorrhiza led us to isolation of magnesium salt of salvianolic acid $\mathrm{B}$ (SAB) that shows concentration dependent potentiation of glucose uptake activity in 3T3-L1 adipocytes. Maximal response achieved by isolated $\mathrm{SAB}$ (concentration: $1 \mathrm{mg} / \mathrm{ml}$ ) was comparable to glucose uptake activity of insulin alone (Figure 4). However, other studies have established that plant extracts and its compounds have the ability to stimulate glucose uptake far better in the presence of insulin than in the absence of insulin $[39,40]$. In contrast, our results demonstrate that, in the absence of insulin, magnesium salt of salvianolic acid B is equally efficacious in stimulating the glucose uptake in 3T3-L1 adipocytes, which suggests that $\mathrm{SAB}$ can increase glucose uptake through insulin independent mechanisms. Cellular uptake of glucose in adipocytes is a tightly controlled process, mediated by a facilitated glucose transporter GLUT4 in adipocytes [41,42]. Understanding the regulation of GLUT4 and glucose transport are found to be extremely challenging, primarily because it involves several signal-transduction pathways that are superimposed on a complex series of vesicle transport process. Insulin binds to a surface receptor on muscle and fat cells and triggers a cascade of signaling events that culminates in GLUT4 translocation [41]. It has been also suggested that many phenolic compounds such as quercetin and its glycosides can stimulate AMPK (AMP activated protein kinase), which ultimately stimulate glucose uptake by activation of GLUT4 [43]. However, further experiments need to be performed to elaborate the complex mechanisms of salvianolic acid B at cellular and molecular levels.

In vivo studies have shown that increase glucose uptake in muscle and fat cells result in amelioration of diabetes mellitus by decreasing the blood glucose levels in diabetic animals [44-46]. Hence, to determine the effect of magnesium salt of SAB (glucose uptake inducer) on hyperglycemia, we performed oral glucose tolerance test (OGTT) in streptozotocin induced diabetic rats. The SAB treated diabetic rats showed a significant decrease in blood glucose levels as compared to the controls over a period of $120 \mathrm{~min}$ (Figure 5). We speculate that the improved glucose tolerance in diabetic rats is due to the stimulatory effects of $\mathrm{SAB}$ on glucose uptake in peripheral tissues. However, methanolic root extracts of salvia species have reportedly shown potent inhibitory action against the enzyme protein tyrosine phosphatase $1 \mathrm{~B}$ (PTP1B) [47,48], which further inhibits insulin signaling; and selective inhibition of PTP1B is a potential drug target for the treatment of type 2 diabetes. Our studies show that purified SAB from S. miltiorrhiza improves glucose tolerance supporting to the evidence that $S$. miltiorrhiza can be exploited further for its anti-diabetic properties. Based on our data and the existing literature, we acknowledge that multiple pathways for $\mathrm{SAB}$ action might be involved for its overall antihyperglycemic activity in vivo and there is evidence that $\mathrm{SAB}$ may reduce diabetes through its protective effect on pancreatic beta-cells [10].

\section{Conclusion}

The present study demonstrated the isolation, characterization, and identification of magnesium salt of salvianolic acid B (SAB) from Salvia miltiorrhiza root. SAB significantly increased the glucose uptake in differentiated 3T3-L1 adipocytes. It also improved glucose tolerance in streptozotocin induced diabetic rats. It therefore provides an important lead for development of salvianolic acid B as hypoglycemic agent for the treatment of diabetes mellitus. Further studies have to be performed to elaborate the complex mechanism of salvianolic acid B in vivo.

\section{References}

1. Roglic G, Unwin N (2010) Mortality attributable to diabetes: estimates for the year 2010. Diabetes Res Clin Pract 87: 15-19.

2. Shaw JE, Sicree RA, Zimmet PZ (2010) Global estimates of the prevalence of diabetes for 2010 and 2030. Diabetes Res Clin Pract 87: 4-14.

3. Wild S, Roglic G, Green A, Sicree R, King H (2004) Global prevalence of diabetes: estimates for the year 2000 and projections for 2030. Diabetes Care 27: 1047-1053.

4. Amin RP, Kunaparaju N, Kumar S, Taldone T, Barletta MA et al. (2013) Structure elucidation and inhibitory effects on human platelet aggregation of chlorogenic acid from Wrightia tinctoria. J Complement Integr Med 10.

5. Williams G (1999) Obesity and type 2 diabetes: a conflict of interests? Int J Obes Relat Metab Disord 23 Suppl 7: S2-4.

6. Liu F, Kim J, Li Y, Liu X, Li J, et al. (2001) An extract of Lagerstroemia speciosa $\mathrm{L}$. has insulin-like glucose uptake-stimulatory and adipocyte differentiationinhibitory activities in 3T3-L1 cells. J Nutr 13: 2242-2247.

7. Zaid H, Antonescu CN, Randhawa VK, Klip A (2008) Insulin action on glucose transporters through molecular switches, tracks and tethers. Biochem J 413 : 201-215.

8. Adams JD, Wang R, Yang J, Lien EJ (2006) Preclinical and clinical examinations of Salvia miltiorrhiza and its tanshinones in ischemic conditions. Chin Med 1: 3

9. Li HB, Lai JP, Jiang Y, Chen F (2002) Preparative isolation and purification of salvianolic acid $B$ from the Chinese medicinal plant Salvia miltiorrhiza by highspeed counter-current chromatography. J Chromatogr A 943: 235-239.

10. Cheng B, Gong H, Li X, Sun Y, Chen H, et al. (2013) Salvianolic acid B inhibits the amyloid formation of human islet amyloid polypeptideand protects pancreatic beta-cells against cytotoxicity. Proteins 81: 613-621.

11. Chen YH, Du GH, Zhang JT (2000) Salvianolic acid B protects brain against injuries caused by ischemia-reperfusion in rats. Acta Pharmacol Sin 21: 463 466 .

12. Li M, Zhao C, Wong RN, Goto S, Wang Z, et al. (2004) Inhibition of shearinduced platelet aggregation in rat by tetramethylpyrazine and salvianolic acid B. Clin Hemorheol Microcirc 31: 97-103.

13. O K, Lynn EG, Vazhappilly R, Au-Yeung KK, Zhu DY, et al. (2001) Magnesium tanshinoate B (MTB) inhibits low density lipoprotein oxidation. Life Sci 68: 903 912.

14. O K, Cheung F, Sung FL, Zhu DY, Siow YL (2000) Effect of magnesium tanshinoate $\mathrm{B}$ on the production of nitric oxide in endothelial cells. Mol Cell Biochem 207: 35-39.

15. Zhou L, Zuo Z, Chow MS (2005) Danshen: an overview of its chemistry pharmacology, pharmacokinetics, and clinical use. J Clin Pharmacol 45: 13451359.

16. Ouyang X, Takahashi K, Komatsu K, Nakamura N, Hattori M, et al. (2001) Protective effect of Salvia miltiorrhiza on angiotensin II-induced hypertrophic responses in neonatal rat cardiac cells. Jpn J Pharmacol 87: 289-296.

17. Kamata K, lizuka T, Nagai M, Kasuya Y (1993) Endothelium-dependent vasodilator effects of the extract from Salviae Miltiorrhizae radix. A study on the identification of lithospermic acid B in the extracts. Gen Pharmacol 24: 977-981.

18. Kamata K, Noguchi M, Nagai M (1994) Hypotensive effects of lithospermic acid B isolated from the extract of Salviae miltiorrhizae Radix in the rat. Gen Pharmacol 25: 69-73.

19. Zhao GR, Zhang HM, Ye TX, Xiang ZJ, Yuan YJ, et al. (2008) Characterization of the radical scavenging and antioxidant activities of danshensu and salvianolic acid B. Food Chem Toxicol 46: 73-81.

20. Liu GT, Zhang TM, Wang BE, Wang YW (1992) Protective action of seven natural phenolic compounds against peroxidative damage to biomembranes. Biochem Pharmacol 43: 147-152.

21. Wu XJ, Wang YP, Wang W, Sun WK, Xu YM, et al. (2000) Free radica scavenging and inhibition of lipid peroxidation by magnesium lithospermate $B$. Acta Pharmacol Sin 21: 855-858. 
22. Yu J, Fei J, Azad J, Gong M, Lan Y, et al. (2012) Myocardial protection by Salvia miltiorrhiza Injection in streptozotocin-induced diabetic rats through attenuation of expression of thrombospondin-1 and transforming growth factorbeta1. J Int Med Res 40: 1016-1024.

23. Manaharan T, Ming CH, Palanisamy UD (2013) Syzygium aqueum leaf extract and its bioactive compounds enhances pre-adipocyte differentiation and 2-NBDG uptake in 3T3-L1 cells. Food Chem 136: 354-363.

24. Roffey BW, Atwal AS, Johns T, Kubow S (2007) Water extracts from Momordica charantia increase glucose uptake and adiponectin secretion in 3T3-L1 adipose cells. J Ethnopharmacol 112: 77-84.

25. Shinde J, Taldone T, Barletta M, Kunaparaju N, Hu B, et al. (2008) Alphaglucosidase inhibitory activity of Syzygium cumini (Linn.) Skeels seed kernel in vitro and in Goto-Kakizaki (GK) rats. Carbohydr Res 343: 1278-1281.

26. Sun Y, Zhu H, Wang J, Liu Z, Bi J (2009) Isolation and purification of salvianolic acid $A$ and salvianolic acid $B$ from Salvia miltiorrhiza by high-speed countercurrent chromatography and comparison of their antioxidant activity. J Chromatogr B Analyt Technol Biomed Life Sci 877: 733-737.

27. Watzke A, O'Malley SJ, Bergman RG, Ellman JA (2006) Reassignment of the configuration of salvianolic acid $B$ and establishment of its identity with lithospermic acid B. J Nat Prod 69: 1231-1233.

28. Muhammad A, Guerrero-Analco JA, Martineau LC, Musallam L, Madiraju P, et al. (2012) Antidiabetic compounds from Sarracenia purpurea used traditionally by the Eeyou Istchee Cree First Nation. J Nat Prod 75: 1284-1288.

29. Spoor DC, Martineau LC, Leduc C, Benhaddou-Andaloussi A, Meddah B, et al. (2006) Selected plant species from the Cree pharmacopoeia of northern Quebec possess anti-diabetic potential. Can J Physiol Pharmacol 84: 847-858.

30. Kumar S, Kunaparaju N, Zito SW, Barletta MA (2011) Effect of Wrightia tinctoria and Parthenocissus quinquefolia on blood glucose and insulin levels in the Zucker diabetic rat model. J Complement Integr Med 8.

31. Ai CB (1988) Stereostructure of Salvianolic Acid B and Isolation of Salvianolic Acid C from Salvia miltiorrhiza. J Nat Prod 5: 145-149.

32. Jiang RW, Lau KM, Hon PM, Mak TC, Woo KS, et al. (2005) Chemistry and biological activities of caffeic acid derivatives from Salvia miltiorrhiza. Curr Med Chem 12: 237-246.

33. Zhou Y, Li W, Xu L, Chen L (2011) In Salvia miltiorrhiza, phenolic acids possess protective properties against amyloid beta-induced cytotoxicity, and tanshinones act as acetylcholinesterase inhibitors. Environ Toxicol Pharmacol 3: $443-452$.

34. Ji X, Tan BK, Zhu YC, Linz W, Zhu YZ (2003) Comparison of cardioprotective effects using ramipril and DanShen for the treatment of acute myocardial infarction in rats. Life Sci 73: 1413-1426.
35. Lin HC, Chang WL (2000) Diterpenoids from Salvia miltiorrhiza. Phytochemistry 53: 951-953.

36. Liu YR, Qu SX, Maitz MF, Tan R, Weng J (2007) The effect of the major components of Salvia Miltiorrhiza Bunge on bone marrow cells. $J$ Ethnopharmacol 111: 573-583.

37. Lu Y, Foo LY (2002) Polyphenolics of Salvia-a review. Phytochemistry 59 117-140.

38. Fang X, Wang J, Zhou H, Jiang X, Zhu L, et al. (2009) Microwave-assisted extraction with water for fast extraction and simultaneous RP-HPLC determination of phenolic acids in radix Salviae Miltiorrhizae. J Sep Sci 32: 2455-2461.

39. Alonso-Castro AJ, Miranda-Torres AC, Gonzalez-Chavez MM, Salazar-Olivo LA (2008) Cecropia obtusifolia Bertol and its active compound, chlorogenic acid, stimulate 2-NBDglucose uptake in both insulin-sensitive and insulinresistant 3T3 adipocytes. J Ethnopharmacol 120: 458-464.

40. Kang Y, Kim HY (2004) Glucose uptake-stimulatory activity of Amomi Semen in 3T3-L1 adipocytes. J Ethnopharmacol 92: 103-105.

41. Bryant NJ, Govers R, James DE (2002) Regulated transport of the glucose transporter GLUT4. Nat Rev Mol Cell Biol 3: 267-277.

42. Jung CY (1996) The facilitative glucose transporter and insulin action Experimental and Molecular Medicine 28: 153-160.

43. Eid HM, Martineau LC, Saleem A, Muhammad A, Vallerand D, et al. (2010) Stimulation of AMP-activated protein kinase and enhancement of basal glucose uptake in muscle cells by quercetin and quercetin glycosides, active principles of the antidiabetic medicinal plant Vaccinium vitis-idaea. Mol Nutr Food Res 54: 991-1003.

44. Buhl ES, Jessen N, Schmitz O, Pedersen SB, Pedersen O, et al. (2001) Chronic treatment with 5-aminoimidazole-4-carboxamide-1-beta-D-ribofuranoside increases insulin-stimulated glucose uptake and GLUT4 translocation in rat skeletal muscles in a fiber type-specific manner. Diabetes 50: 12-17.

45. Lee JO, Lee SK, Jung JH, Kim JH, You GY, et al. (2011) Metformin induces Rab4 through AMPK and modulates GLUT4 translocation in skeletal muscle cells. J Cell Physiol 226: 974-981.

46. Leick L, Fentz J, BiensÃ, RS, Knudsen JG, Jeppesen J, et al. (2010) PGC1 alpha\} is required for AICAR-induced expression of GLUT4 and mitochondrial proteins in mouse skeletal muscle. Am J Physiol Endocrinol Metab 299: E456-465.

47. Han YM, Oh H, Na M, Kim BS, Oh WK, et al. (2005) PTP1B inhibitory effect of abietane diterpenes isolated from Salvia miltiorrhiza. Biol Pharm Bull 28: 1795-1797.

48. Hu XX, Yang YF, Zhang YT (2009) Preliminary exploration of inhibitory activities of Salvia species on PTP1B. Yao Xue Xue Bao 44: 440-442. 